\title{
LXVII. Remarks tending to facilitate the analysis of spring and mineral waters
}

\author{
John Dalton
}

To cite this article: John Dalton (1821) LXVII. Remarks tending to facilitate the analysis of spring and mineral waters, Philosophical Magazine Series 1, 58:282, 291-296, DOI: $10.1080 / 14786442108652629$

To link to this article: http://dx.doi.org/10.1080/14786442108652629

里 Published online: 27 Jul 2009.

Submit your article to this journal $₫$

Џ Article views: 3

Q View related articles $\square$ 
the head of the former. The number expressing the size of the shot, the weight of the charge, and the diameter of the barrel for which they are intended, are then marked on the cartridge thus : i. e. No. 4 shot $2 \frac{1}{4} \mathrm{oz}$. for barrel 72 diameter. This is essential, as some cartridges remain in stock many years, and, although promiscuously mixed together, are easily separated.

If the above occupies too much space to be admitted at length, please to make such extracts as you think fit.

While on the subject of fowling-pieces. I beg leave to remark, that although numerous excellent sporting guns are produced; yet no scientific principle has been laid down, on which to proceed with a certainty of obtaining this desirable end. From a variety of experiments, $I$ am induced to believe there is a certain ratio between the length of the barrel and diameter of the bore, which gives the maximum of perfection. Perhaps some of your scientific readers will favour the public with some observations on this subject.

I am, sir, your obedient servant,

Old Ford, Oct: 12. 1821.

Jos. SteEvens.
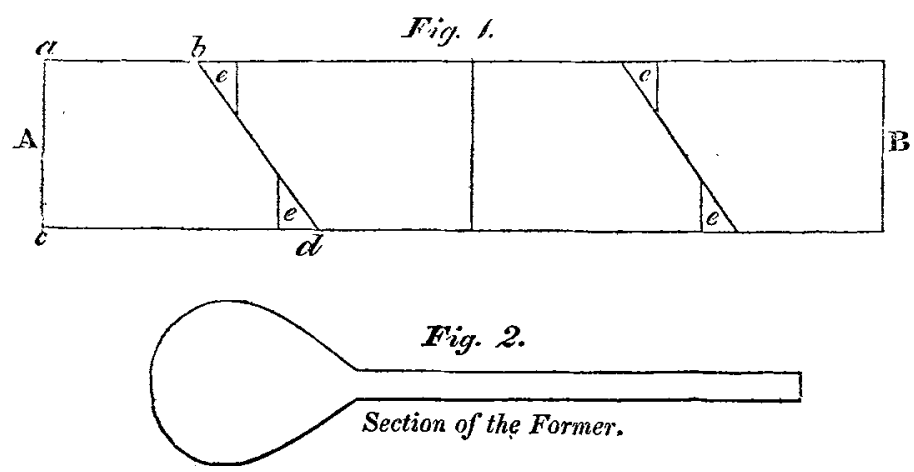

LXVII. Remarks tending to facilitate the Analysis of Spring and Mineral Waters. By JoHn DaLton *.

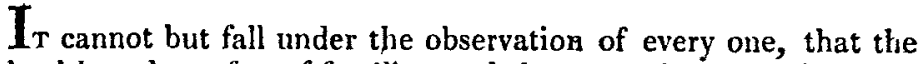
health and comfort of families, and the conveniences of domestic life, are materially affected by the supply of that most necessary article, water. The quality of water is undoubtedly of great importance in the arts of brewing, baking, and various others connected with the preparation of food; as also in the washing and

* From the Metnoirs of the Literary and Philosophical Society of Manchester,

$$
\text { O } 02
$$

bleaching 
bleaching of linen and cotton, and in other operations where cleanliness is the object in view. Many of the manufactories are materially interested likewise in the qualities of water, and in the methods of rendering it subservient to their exigencies when it happens to be presented to them in an obnoxious form. On all these accounts I thought it might be of some service to offer a few remarks on the subject, which, perhaps, may benefit those who have not made the science of chenistry a peculiar object of study.

Most writers consider the analysis of waters as a problem requiring great skill and acquaintance with chemistry; but the modern improvements in that science have rendered it much less so than formerly. It is true, that the variety of elements sometimes found in water, and the extremely small quantities of them, are discouraging circumstances when the object of analysis is to ascertain both the kind and quantity of these foreign elements. They may both, however, be investigated without much labour, when proper means are used; and, perhaps, a little practice may render a person qualified to undertake the task, who is no great adept in chemical science in general.

Most spring water that is obtained by sinking some depth into the earth, contains lime held in solution by some one or more acids, particularly the carbonic and sulphuric acids.

It is to these salts, the carbonate and sulphate of lime principally, that spring water owes its quality of hardness, as it is called; a very singular and astonishing quality, when it is considered as produced by so extremely small a portion of the earthy salt. The other earthy/ salts, or those of magnesia, barytes, and alumine, produce the same effect nearly, but they are rarely met with, compared with those of lime.

When any earthy salt is disselved in pure distilled or rain water, it increases the specific gravity of the water; but, in the instance of spring water in general, this test is rendered of little use, because the increase of sp. gr. is so small as almost to elude the nicest instrument that can be made. I have, however, an instrument, made by an artist in this town, which is nothing more than the common glass hydrometer, but with an unusually fine small stem, that shows the superior gravity of spring water. It cannot, indeed, be brought in competition with other methods for ascertaining the relative hardness of spring water, but it is a most useful instrument in other departments of chemical investigation, particularly in determining minute portions of residual salt after precipitations *. It may well be conceived, that the

* The scale of the lyddrometer is one inch and a half long, and it is divided into $25^{\circ}$, each degree corresponding nearly to 0004 ; the difference between distilled water and common spring water is usually about $1^{\circ}$ on the instrument; and that between distilled or rain water and the strongest lime water is $4^{\circ}$. 
sp. gravity cannot constitute a test of the hardness of water, when we find that one grain of earthy salt, dissolved in 2000 grains of pure water, converts it into the hardest spring water that is commonly found.

We shall now proceed to notice some of the most useful tests in the analysis of waters.

1. Soap Test.-When a piece of soap is agitated in distilled or pure rain water, a part of it is dissolved, producing a milky liquid, which continues for many days unaltered. But when soap is agitated with hard spring water, the milkiness produced almost instantly degenerates into a curdy substance, which rises to the surface, and leaves the liquid below nearly transparent. This curdy substance is understood to be the earth of the salt combined with the oil of the soap. It has a glutinous, unpleasant feel when rubbed upon the hands, and soils glass and other vessels so as to require hard pressure of a cloth to remove it. Though this test sufficiently distinguishes hard water from soft or pure water, it is not equal to form an accurate comparison of the hardness of two kinds of water.

2. Lime-water Test.-Most spring water, fresh from the well, will exhibit milkiness by lime-water; this is usually occasioned by the water holding supercarbonate of lime in solution; the addition of lime-water reduces the supercarbonate to carbonate, which is insoluble, and falls down in the state of a white granular powder. When a spring contains nothing but supercarbonate of lime, which is the case with the water of an excellent pump in this neighbourhood, lime-water is the only test wanted to ascertain the proportion of salt in it. Let a given portion of the spring water be-saturated by lime-water, adding it as long as milkiness ensues ; the carbonate of lime is precipitated, and may be determined by the usual means. I find it, however, rather preferable to add a small excess of lime-water to secure the precipitation of the whole acid : when the salt has subsided, the clear liquid may be poured off, and tested by an acid, and the salt may be dissolved hy test muriatic or nitric acids. Thus the whole quantity of lime will he found; from which, deducting that added in lime-water, there will remain the lime in the spring water originally combined with the carbonic acid. In this way I find the supercarbonate of lime, in five ounces of the water above mentioned, to eonsist of

.49 lime,

.77 carb. acid,

\section{$1 \cdot 25$}

being about one grain of salt in 2000 of water. This kind of water is hard, and curdles soap; but it is much softened by boiling, and deposits the incrustation so often found in kettles, \&c. 
If water contains sulphate of lime along with supercarbonate, the same treatment may still be adopted as far as respects the superearbonate. I have recently found, with some surprise, that the surpercarbonate of lime, as I call it, existing in waters, or made artificially, is rather an alkaline than acid compound.

3. Acetate and Nitrate of Lead Tests.-These salts are easily obtained in great purity, and are excellent tests for carbonic and sulphuric acid, which they precipitate immediately in combination with the lear. If the precipitate be treated with uitric acid, the carbonate of lead is instantly dissolved, and the sulphate of lead (if present) remains undissolved, and may be collected and dried ; from which the quantity of sulphuric acid may be determined.

4. Nitrate and Muriale of Barytes Tests.-When the object is to ascertain the presence of sulphuric acid, either free or combined, these are the best tests. The sulphate of barytes is perhaps the most insoluble salt known. Even rain water collected from slated houses, though softer than spring or river water, exhibits by these tests one grain of sulphuric acid in 20 or 30 thousand grains.

5. Oxalic Acid Test.-When the object is to obtain the lime, either free or combined, in any water, this is the best test. It may be proper to add a little ammonia in some cases of combined lime. The oxalate of lime slowly precipitates in the state of an insoluble salt. The quantity of lime may be ascertained, either by collecting the precipitate, or by carefully and gradually adding the due quantity of acid and no more, when the strength of the acid has been previously ascertained.'

6. Nitrates of Silver and Mercury Tests.-These are tests of muriatic acid or of muriates ; the muriates of silver and mercury are formed, both insoluble salts. It does not often happen that spring waters contain notable proportions of the muriatic acid either free or combined.

7. Sulphuretted Hydrngen-water and Hydro-sulphurets.These are excellent tests for lead, mercury, and several metals, giving peculiar insoluble precipitates of the sulphurets of those metals. One grain of lead precipitated by sulphuretted hydrogen, would be sufficient to give a great many gallons of water dark brown tinge. When sulphuretted hydrogen is found in mineral waters, as those of Harrowgate; it may be known by the smell; but solutions of lead are much superior tests, giving a black or brown tinge to such waters immediately.

8. Tincture of Galls and Prussiates of Potash and Lime Tests.-These are proper for the detection of iron, the former giving a black precipitate and the latter a blue one; but a portion of the solution of oxymuriate of lime requires to be added pre- 
'vionsly to the water, if it contains the green oxide of iron in solution, in order to convert it to the red oxide.

There are many other tests than those I have enumerated, but they are more than can usually be wanted in the analysis of ordinary springs. My ohject is not to give a catalogue of tests, but to show in what manner their application may be improved, and reduced to a system intelligible to moderate proficients.

The improvements I would propose in the use of tests are, that the exact quantities of the ingredients in each test should be previousiy ascertained and marked on the label of the bottle; this might easily be done in most of them in the present state of chemical science. We should then drop in certain known quantities of each from a dropping tube graduated into grains, till the required effect was produced; then from the quantity of the test required, the quantity of saline matter in the water might be determined without the trouble of collecting the precipitate; or, if this was done, the one method would be a check upon the other.

I shall now close this imperfect sketch by a few observations and experiments which I have noticed in the course of the present week relative to the subject before us.

I assayed the water supplied by the Manchester water-works, and found it nearly as I expected; river water is most commonly softer than spring water, and harder than rain water. This is the case with the water in question. It contains a very little sulphate of lime and some carbonate; but only one half of the earthy matter that the above-mentioned pump water contains. It curdles a little with soap, but gives no precipitate with lime-water. It contains about 1 grain of earthy salts in 4000 of water.

When spring water contains supercarbonate of lime, boiling it precipitates the greater part of the carbonate, and expels the excess of acid. Hence the jurring of pans and tea-kettles with this kind of water. By boiling the water it is of course rendered much softer than before. It may then be used for washing, scarcely curdling soap; but it still contains about $\frac{1}{3}$ of the earthy salt, and gives milkiness with acetate of lead. If a water contain only sulphate of lime, boiling does not, I apprehend, soften it at all.

When spring water is used by manufacturers for washing, \&c. it is advantageous to have it some time exposed to the atmosphere, in a reservoir with a large surface. This exposition suffers the carbonic acid in part to escape, and the carbonate of lime to piecipitate; and in some degree supersedes the necessity of boiling the water. The more any spring is drawn from, the softer the water becomes, it should seem. I have this morning examined a spring which yields many thousand gallons every cay. The water is comparatively soft; it does not curdle scareely 
at all with soap : it is very nearly as soft as the before-mentioned pump water boiled. The hardness in it arises from a little sulphate of lime and a little carbonate.

One of the most striking facts I have observed is, that all spring water containing carbonate or supercarbonate of lime, is essentially limy or alkaline by the colour tests. And this alkalinity is not destroyed tili some nore powerful acid, such as the sulphurie or muriatic, is added, sufficient to saturate the whole of the lime. Indeed these acids may be considered as sufficient for tests of the quantity of lime in such waters, and nothing more is required than to mark the quantity of acid necessary to neutralize the lime. It does not signify whether the spring water is boiled or unboiled, nor whether it contains sulphate of lime along with the carbonate; it is still limy in proportion to the quantity of carbonate of lime it contains. Agreeably to this idea, too, I find that the metallic oxides, as those of iron or copper, are thrown down by conmon spring water just the same as by free lime. Notwithstanding this, carbonate of lime in solution with watey contains twice the acid that chalk or limestone does. I fully expected the supercarbonate of lime in solution to be acid. "But it is strongly alkaline, and scarcely any quantity of carbonic acid water put to it will overcome this alkalinity. Pure carbonic acid water is, however, acid to the tests. I could not be convinced of the remarkable fact stated in this paragraph, till I actually formed supercarbonate of lime, by supersaturating lime-water in the usual way, till the liquid from being milky became clear. It still continued limy, and was even doubtfully so when two or three times the quantity of acid was added. It should seem, then, to be as inpossible to obtain a neutral carbonate of lime, as it is to obtain a nettral carbonate of ammonia in the sense here attached to the word neutral.

1.XVIII. Notices respecting New Books.

\section{Preparing for Publication.}

$A_{N}$ Essay on the Strength and Flexibility of Cast Iron; with Practical Rules and Tables for various Purposes in Eugineering and Architecture; Remarls on the Forms of greatest Strength; and, an Account of some new Experiments on the Strength of Iron. By Thomas Tredgold, Author of "Elementary Principles of Carpentry," and of the Article Joinery in the New Supplement to the Encyclopadia Britannica.

Mr. Gill, for many years one of the Chairmen of the Committee of Mechanics in the Society for the Encouragement of Arts, Manufactures, and Commerce, in the Adelphi, assisted by a 